\title{
VALUE-AT-RISK BASED APPROACH FOR CURRENCY HEDGING
}

\author{
Rachna Khurana \\ Chief Executive Officer \\ Southern Ridges Capital \\ 8 Robinson Road, Singapore 048547, USA \\ E-mail: rachna.khurana@ southernridgescapital.com \\ Umang Khetan \\ PhD Candidate \\ University of Iowa \\ Tippie College of Business, Iowa City, IA 52242, USA \\ E-mail: umang-khetan@uiowa.edu
}

\begin{abstract}
Corporate FX risk management has gained complexity with an increased number of currencies involved and varying correlations among them. Existing literature has highlighted the need to account for cross-currency correlations when optimizing hedge ratios for portfolio management (Dowd, 1999). In this paper, we propose a Value-at-Risk (VaR) based model to estimate the optimal hedge ratio for a multi-national corporate that aims to minimize the cost of hedging at a given tolerance level of expected loss arising out of FX movement. The paper illustrates both parametric and historical methods of VaR estimation at a portfolio level as the first step in risk management. As a second step, an efficient-frontier is derived based on the expected VaR level at various hedge ratios and compared with associated hedge cost. The benefits of this approach include: identification of net exposures after correlations among currencies are accounted for in order to avoid duplication of hedges, and condensation of the parameters governing hedging decision into a single, intuitively-appealing number. The paper also highlights the need to frequently update the model's assumptions as currency correlations and corporate exposures remain dynamic.
\end{abstract}

Keywords: Value-At-Risk, FX Risk Management, Correlation, International Finance.

JEL Classification Codes: C10, F31, G32, M20.

\section{INTRODUCTION}

Increase in cross-border flow of capital and trade has diversified the sources of cash flow for multi-national corporations. These cash flows tend to be denominated in varying currencies, often different from the functional currency of the corporation in which it draws its books of accounts. As a result, corporate treasuries have to manage multi-currency exposures while controlling for cost of hedging. 
Existing literature on corporate FX risk management has focused on the merits of undertaking derivative transactions for minimizing cash flow volatility. Dufey and Srinivasulu (1983) were among the earliest proponents of corporate FX risk management, arguing that firms can hedge more cheaply than individual shareholders and protect the latter in times of financial distress. Nain (2004) finds there to be strategic motives for FX risk management that insulates corporate from input price fluctuations in markets with inelastic output prices. Smithson and Simkins (2005) conducted a survey that found that $92 \%$ of Fortune 500 companies believed that financial risk management adds value to shareholders. In light of these findings, it is important to adapt risk management strategies in line with the evolving complexities in currency markets and diversified nature of cash flows. This paper highlights one such approach: the Value-at-Risk.

Value-at-Risk (VaR) is a globally recognized framework in banks and financial institutions. The methodology became an industry standard after Morgan (1996) published the Risk Metrics framework in 1992. While the financial industry has adopted variations of the framework and several papers and books have been written on implementation and limitations (see for instance Dowd, 1999), this paper is the first to apply the framework to corporate FX risk management. The strength of the framework lies in its ability to condense various sources of FX risk into a single metric that can be understood at various levels in an organization.

$\mathrm{VaR}$ as a risk assessment parameter has also found applicability in asset management literature. Marshall and Siegel (1996) consider different approaches to portfolio risk management based on the central idea of VaR, as detailed in Morgan's Risk Metrics. In this paper, we illustrate the parametric and historical cash-flow methodologies to estimate VaR when a corporate has exposures in multiple currencies that are less-than-perfectly correlated with one another. Rockafellar and Uryasev (2000) proposed a conditional VaR model that focuses only on downside risk, since that is essentially what an investor tries to protect against. In our paper, however, we assume a corporate philosophy of mitigation of volatility while keeping the cost at a reasonable level, and hence do not go down the conditional VaR route.

At the outset, an organization often evaluates the benefits of hedging currency risks. Global treasurers typically face a dilemma because hedging and speculating can be two sides of a coin depending on the view of the organization or that of the senior management. Copeland and Copeland (1999) illustrate that variance minimization is not the only objective way of assessing a hedge program; the impact of a hedge program on business disruption and the drift in operating cash flow caused by the cost of FX hedging must also be considered. In this paper, we consider the example of an Indian exporter that expects to earn USD in the future and can hedge the currency risk by selling USD against INR under a forward contract. If INR were to appreciate in the future, the mark to market on the contract would be positive and the company would benefit by having locked in a rate for its future receivables. On the flip side, if INR depreciates, the mark to market on the contract would be negative. The contract was to fix a rate for its future receivables, and hence is technically not a loss for the company. However, the senior management or shareholders can view it as an opportunity loss where the company could have received higher INR value in absence of the forward contract. If the firm were to opt for an Option contract instead, to take advantage of a possible favorable currency movement, it would have to pay a premium which adds to hedge costs. There are other costs associated with hedging as well which need to be considered, including manpower and operational overheads. Therefore, it is important for all levels in the organization to clearly set the objectives of a hedging policy to avoid any conflicts in the aftermath of a hedge performance. It is also important for the policy 
and tools to be simple to understand and evaluate. It is with this motivation that a simple metric must be used to evaluate hedge decisions against.

We propose the use of VaR to arrive at an assessment of materiality of risks. The simplicity of $\mathrm{VaR}$ measurement greatly facilitates reporting of risks to senior managers and directors in a standard format. VaR represents the potential loss that can be expected on a portfolio of assets, associated with a specified level of confidence, based on the correlations among assets and their respective volatilities. The example of an Indian corporate used in this paper follows a confidence level of $95 \%$, but variations around it can be easily incorporated Hendricks (1996) for other variants of the model. As with any quantitative tool, there are limitations such as reliance on historical data and inability to predict fat-tail events. We discuss some of these issues in the last section of the paper.

We set the corporate to centrally manage its FX risks where it can consolidate its exposures and optimize the hedge ratio. The first step in the process is risk evaluation. We develop a framework here to identify various exposures and quantify the risks in terms of impact on the firm's profitability, using a simple VaR metric. The second step is to decide how much of the exposure identified should be hedged using FX derivatives. A conservative approach that does not account for cross-currency correlations is to hedge each currency exposure fully - in the spirit of complete mitigation of cash flow volatility caused by FX movements. However, this can result in large costs for the organization including transaction costs, credit limit utilization, margining requirements, and operational overheads. Particularly for companies having exposures in emerging market currencies, such costs can be material. We propose a cost-benefit trade-off model that obviates hedging of offsetting exposures and focuses on the net currency risk faced by the corporate. The cost of hedging this net exposure is assessed against the VaR achieved at different levels of hedge ratio. This results in an efficiency frontier along which the corporate can determine the cost-efficient optimal hedge ratio and the associated $\mathrm{VaR}$ at that level. The model also offers flexibility to a corporate that wishes to target a certain VaR level and accordingly determine the hedge ratio. Targeting a zero VaR would need $100 \%$ hedge ratio of net exposure. The paper therefore provides a scientific way to determine optimal hedge ratios for multinational corporations and accounts for the key variables of FX exposures, expected cash-flow volatility, and hedge cost.

The paper concludes with a discussion on the limitations of using $\mathrm{VaR}$ as a standalone quantitative tool. We take the example of COVID-19 crisis, which was a tail-risk event that a $\mathrm{VaR}$ model can only provide partial protection against. Other limitations of the proposed approach include the need to regularly update the model parameters. Companies' risk profile in terms of currency exposures undergoes changes from time to time, and a correlation among currencies is also not static. The model, once constructed and implemented, can be updated with little effort.

A potential extension of this model and that of the paper would be to include other asset classes that the corporate has exposure to, such as interest rates and commodities, and that have non-zero correlation with FX. The rest of this paper is organized as follows: Model, Empirical Illustration, and Discussion on limitations of the model and best practices for hedging, and Conclusion. This section ends with a brief summary of key foreign exchange risks for a corporate, as below. 


\section{Key Foreign Exchange Risks}

Every transaction or potential transaction which result in an inflow or outflow in foreign currency is a risk for a company. Most companies would identify these risks in below broad categories:

- Current Account Transaction Risk: This arises due to current payable/receivable and net income in foreign currency. This is part of the consolidated profit and loss statement. For instance, a US based machine tools manufacturer selling products in Europe may have receivables in EUR and exposure to EURUSD currency volatility as the functional currency of the US based manufacturer is US Dollar. Another example could be a US based company having a subsidiary in Singapore for its Asia business and consolidating the net income from Singapore (in SGD).

- Capital Account (Foreign Currency Debt) Risk: This is an important risk to consider as companies may tap various foreign markets for meeting their borrowing needs. These could be long tenor bonds/loans and any significant FX moves could result in a much larger liability for the company.

- Net Investment Risk: This is the risk arising from investments in foreign subsidiaries whose reporting currencies may be different from that of its parent. In most cases, this is treated as "Other comprehensive Income" thereby affecting Balance Sheet and not the Income Statement.

\section{MODEL}

We consider a firm with CARA utility function that seeks to maximize expected wealth in the following period. The utility function of the firm is given by

$$
U=-\exp (-a W)
$$

Where $a$ is the coefficient of risk aversion and $\mathrm{W}$ is the level of wealth achieved in period $t+1$. We take $a$ as exogenously given and proceed to analyze the determination of wealth $W$.

Wealth in period $t+1$ is composed of cash flows arising into or out of currencies other than the home currency of the firm. While the cash flow is certain in the currency in which it is denominated (for example, export contracts or outbound investment flows), there is uncertainty around the future FX rate at which such cash flows will eventually occur ${ }^{1}$. Therefore, the corporate attempts to maximize the below wealth function that is parametrized by cash flow in foreign currency and the expected spot rate in period $t+1$

$$
\max \mathrm{E}\left[-\exp \left(-a\left(x^{i} * S_{t+1}^{i}\right)\right]\right.
$$

Where $x^{i}$ is the cash flow in foreign currency $I$ and $S_{t+1}^{i}$ is the expected spot rate at the time of actual conversion. Note that we do not place a non-negativity constraint on $x$ because it can be both an inflow and an outflow from the corporate's perspective. However, for the rest of the analysis below, we consider the case of a firm that exports in terms of currency $i$ to earn a

\footnotetext{
${ }^{1} \mathrm{We}$ assume $100 \%$ certainty of cash flow in the foreign currency to keep the model tractable. However, risk of contract non-performance can be incorporated by multiplying the cash flow with a certainty factor and proceeding with the analysis as described. Our results continue to hold in such scenarios.
} 
positive cash flow in foreign currency $\left(x^{i}>0\right)$ and benefits from a higher expected spot rate of conversion.

Now let us say that the firm chooses to hedge a certain portion of its expected cash flow so as to not depend entirely on the vagaries of FX market in setting the conversion rate when the cash flow becomes due. Let $\alpha^{i}$ be the proportion of cash flow that is not hedged, and consequently $\left(1-\alpha_{i}\right)$ is the proportion that is hedged at a certain rate of $F^{i}$ with associated hedge cost of $m^{i}$. Then, the expected wealth is given by

$$
W^{i}=\mathrm{E}\left[x^{i} *\left(\alpha^{i} S_{t+1}^{i}+\left(1-\alpha^{i}\right)\left(F^{i}-m^{i}\right)\right)\right]
$$

Subject to the constraints that

$$
0 \leq x^{i}, \quad 0 \leq \alpha^{i} \leq 1
$$

The term $\left(F^{i}-m^{i}\right)$ can be understood as the net rate realized by the firm that is composed of (i) in case of an option, at least the strike price less premium, or (ii) in case of a forward, the forward rate less transaction costs.

Further, assume $S_{t+1}^{i}$ to be normally distributed with mean $\mu$ and variance $\sigma^{2}$, i.e. $S_{t+1}^{i} \sim N\left(\mu, \sigma^{2}\right)$. Substituting equation (2) and the foregoing distribution parameters into the exponential function (1), we arrive at the firm's objective function as

$$
\max _{\alpha^{i}}-\exp \left(-a x^{i}\left(\alpha^{i} \mu+\left(1-\alpha^{i}\right)\left(F^{i}-m^{i}\right)\right)+\frac{1}{2} a^{2} x^{2} \alpha^{i^{2}} \sigma^{2}\right)
$$

Maximizing this function is akin to minimizing the power of the exponential. We take the first order condition of the power term with respect to $\alpha^{i}$ and arrive at its optimal value as below

$$
\alpha^{i}=\frac{\mu-F^{i}+m^{i}}{a x^{i} \sigma^{2}}
$$

This is the first key result in our paper; the proportion of cash flow in foreign currency that the firm chooses to keep unhedged, $\alpha^{i}$, goes up as: (i) the volatility of the FX pair goes down, (ii) the difference between the expected spot rate and the hedged rate goes up (in this case, the forward premium goes down), (iii) the hedge cost goes up, and (iv) the firm's coefficient of risk aversion goes down. All of these conclusions make intuitive sense. Consequently, the firm arrives at the optimal hedge ratio considering the FX volatility, expected spot rate (which may be the same as current spot rate), the forward quote available from a dealer bank, and the associated option premium or transaction costs.

Now we can consider these results at an aggregate level for all currency pairs put together. The corporate can treat each stream of cash flow affected by an FX pair separately, thereby deciding on how much to hedge for each currency pair. Such an approach assumes that all the FX pairs that the firm has exposure to are independently and identically distributed (iid). While the assumption of identical distribution may be plausible (at least to the extent the currency pairs can be classified as G10 or EM), the assumption of independence among FX pairs is clearly not. We show in the empirical section below the correlation between a sample of currency pairs and find that they are almost always non-zero. This is understood to be the case 
because similar macro-factors move currencies, such as geopolitical developments, commodity prices, risk sentiment that drives portfolio flows, and macro-economic data. Therefore, we refine the approach of the corporate to account for cross-currency correlations when determining the exposure that needs to be hedged, and then optimizing its hedge ratio of the net exposure.

We know from literature that portfolio variance is not a simple summation of variances of individual securities. We apply the same reasoning in the context of a portfolio of currencies that the corporate has exposure to. Consider a portfolio of $n$ currency pairs. Let $\operatorname{Cov}(i, j)$ be the covariance between currencies $i$ and $j$, derived from a covariance matrix that is empirically derived using historical data for all the currencies. Then, the portfolio variance is given by,

$$
\sigma_{p}^{2}=\sum_{i=1}^{n} w_{i}^{2} \sigma_{i}^{2}+\sum_{i=1}^{n} \sum_{j=1}^{n} w_{i} w_{j} \operatorname{Cov}(i, j)
$$

Where $w_{i} w_{j}$ is the product of the relative weight of the currencies in the portfolio.

Motivated by the portfolio variance theory, we introduce VaR as a condensed numerical representation of the risk faced by the corporate considering all currency exposures together. This can substitute for the individual currency variance that we considered in equation (4) when deciding on the optimal hedge ratio.

Value-at-Risk is an attempt to provide a single number summarizing the total risk in a portfolio of financial assets. It gives the maximum loss that an institution can expect to face with a certain confidence level over a specific horizon at a portfolio level. Controlling for a certain tolerance level of $\mathrm{VaR}$, the corporate can ascertain how much of the net currency exposure it should hedge. Generally, the corporate can compare the level of VaR with associated cost of hedging in the numerator of equation (4) to draw an efficient frontier of hedge ratio. We detail this approach in the next section. This section concludes with a brief overview of two VaR estimation methodologies.

\section{VaR Methodologies}

\section{Historical Method}

This method uses historic market data to create theoretical portfolio of the exposure profile at various points in the past. It calculates hypothetical returns for the current portfolio using actual historic market conditions over a certain period of the past, such as the past one year. For instance, we can calculate the change in portfolio value over one year holding period, observed daily, which provides the daily market value change of the portfolio.

Once we arrive at a hypothetical return for each day, we can calculate the average of the worst twenty days (from a sample set of 252 working days) for $95 \%$ confidence to give us the resulting VaR. Other confidence intervals typically used in literature are $97.5 \%$ and $99 \%$.

Historical method requires a significant amount of daily rate history and incorporates tail risk only to the extent of what may have actually occurred in history. However, as a concept this method is easy to understand and implement, with limited mathematical computation. Also, correlations and standard deviations need not be separately estimated because the change in portfolio value automatically incorporates them. 


\section{Parametric method (Variance - Covariance)}

This method relies on a variance-covariance matrix for all currencies in the portfolio and estimates the portfolio standard deviation using equation (5).

Where,

$$
\operatorname{VaR}(\$)=\propto * \sqrt[2]{t} * \sigma_{p} * \text { Exposure }(\$)
$$

$\propto \quad=\quad$ Number of standard deviations from the mean for given confidence level

- $95 \%$ confidence interval: 1.65

- $97.5 \%$ confidence interval: 1.96

- $99 \%$ confidence interval: 2.33

$\mathrm{t} \quad=\quad$ Time period in days

$\sigma_{p} \quad=\quad$ Daily standard deviation

The benefit of parametric method is that it doesn't involve analyzing extensive historical data (only volatility and correlation data is required). This makes it applicability easier across new and evolving portfolios. A disadvantage is that it may be less accurate for skewed distributions or distributions with fat tails, because of its inability to learn from past events.

\section{EMPIRICAL ILLUSTRATION}

We consider an electronics manufacturer based out of India, with exports and imports denominated in EUR, GBP, JPY and USD, and foreign currency debt in EUR and USD. The below tables summarize the exposures. All exposures have been converted into USD equivalent to enable comparison.

Table 1. exposure summary (amounts in USD million equivalent)

\begin{tabular}{|l|c|c|c|}
\hline Trade Exposures & Exports & Imports & Net Imports \\
\hline EUR & 100 & 10 & -90 \\
\hline JPY & 250 & 0 & -250 \\
\hline USD & 300 & 50 & -250 \\
\hline GBP & 50 & 100 & 50 \\
\hline \hline Foreign Currency Debt & Amount & Tenor & \\
\hline EUR & 500 & $10 \mathrm{y}$ & \\
\hline USD & 200 & $5 \mathrm{y}$ & \\
\hline & & & \\
\hline $\begin{array}{l}\text { Consolidated Exposure affecting the Income } \\
\text { Statement }\end{array}$ & Net Payables & & \\
\hline EUR & 410 & & \\
\hline JPY & -250 & & \\
\hline USD & -50 & & \\
\hline GBP & 50 & & \\
\hline
\end{tabular}


The company starts with an analysis of its net exposure which is summarized in the third table above. In USD terms, the largest exposure is a net EUR payable of 410 million, followed by a JPY receivable of 250 million. Smaller exposures are payable of 50 million in GBP and an equal amount of receivable in USD. We assume the timing of these exposures to coincide. Without looking at currency correlations, the corporate treasury would seek to hedge a certain portion of each currency's exposure individually. However, we have two potential offsets available that the VaR model can capture. First, due to current and capital account exposures running in opposite directions for both EUR and USD, the company has EUR payable and USD receivable. Additionally, there is a net JPY receivable and GBP payable. In all, the net exposure of the four currency pairs can be consolidated into a common currency unit (say, INR or USD) to arrive at the final, offsetting exposure number.

Second, there are correlations among currencies which increase or decrease the overall risk faced by the corporate. Figure 1 below illustrates rolling correlation for a tenor of 1 year for combinations of these currency pairs.

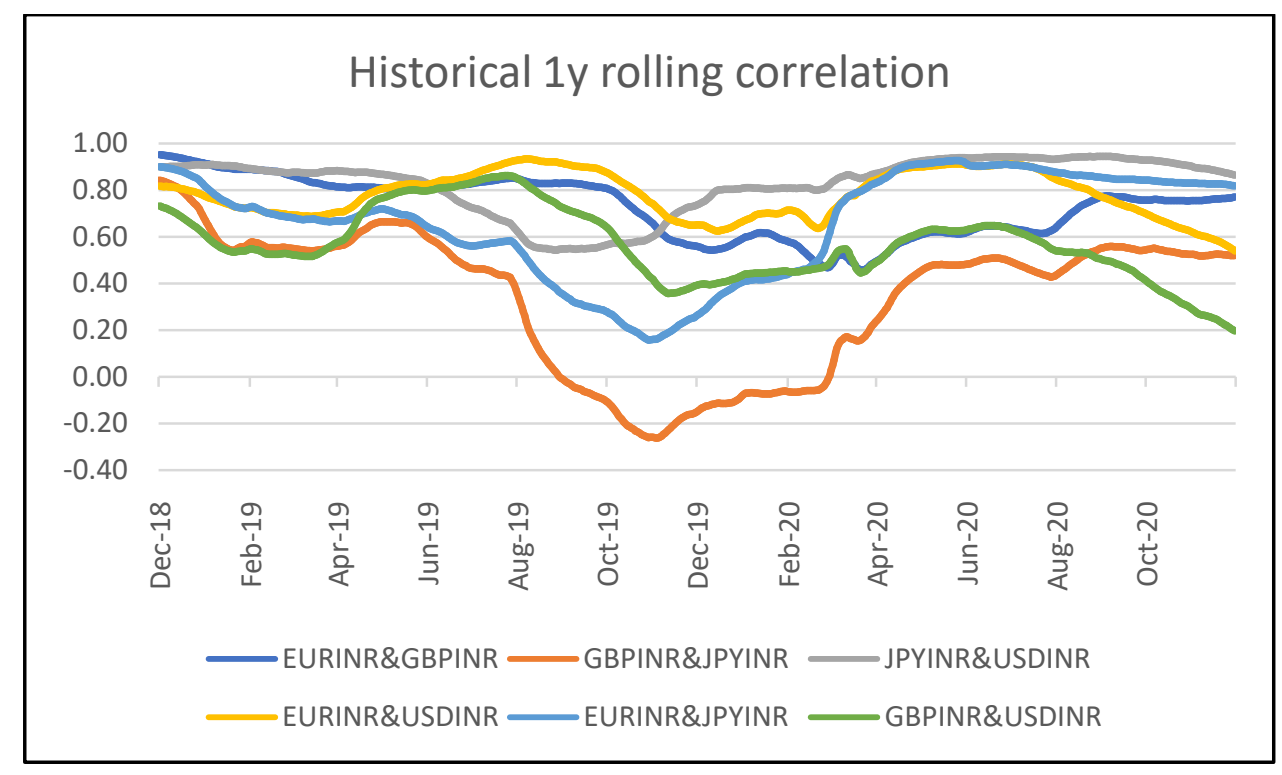

Figure 1. Historical rolling correlation between select currencies Data Source: Bloomberg

Looking at correlations, amongst the major exposures, EURINR and JPYINR are offsetting exposures and are positively correlated. These two pairs therefore provide an offset to the company and obviate the need to hedge separately. Likewise, EURINR and USDINR are strongly positively correlated and have offsetting cash flows, thereby further reducing the net amount that the company needs to hedge. However, the positive correlation between EURINR and GBPINR with same direction of exposure (net payable in both) means that these exposures add up to overall risk and must be aggregated. We summarize these results into an intuitively appealing $\mathrm{VaR}$ measure using both historic and parametric estimation methods in figures 2 and 3. These figures show, at various levels of confidence, what is the expected daily loss to the company at a portfolio level if the currencies were to move from their present levels. All correlations and volatilities are encapsulated in a single number that provides the basis for the 
next step of hedge decision. Historical volatility pattern in these currencies, which drives the estimate of $\mathrm{VaR}$ under both methods, is displayed in Figure 4.

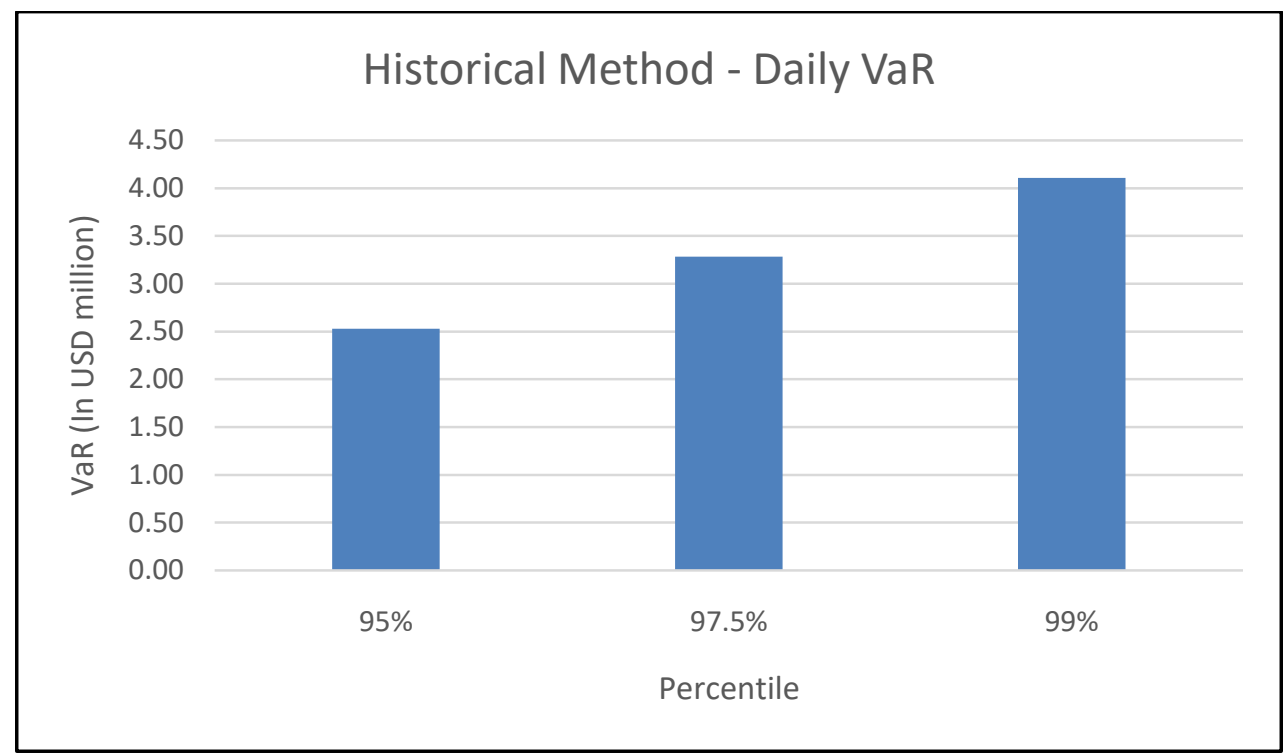

Figure 2. Daily VaR in USD (million) using Historical method at three levels of confidence Data Source: Bloomberg.

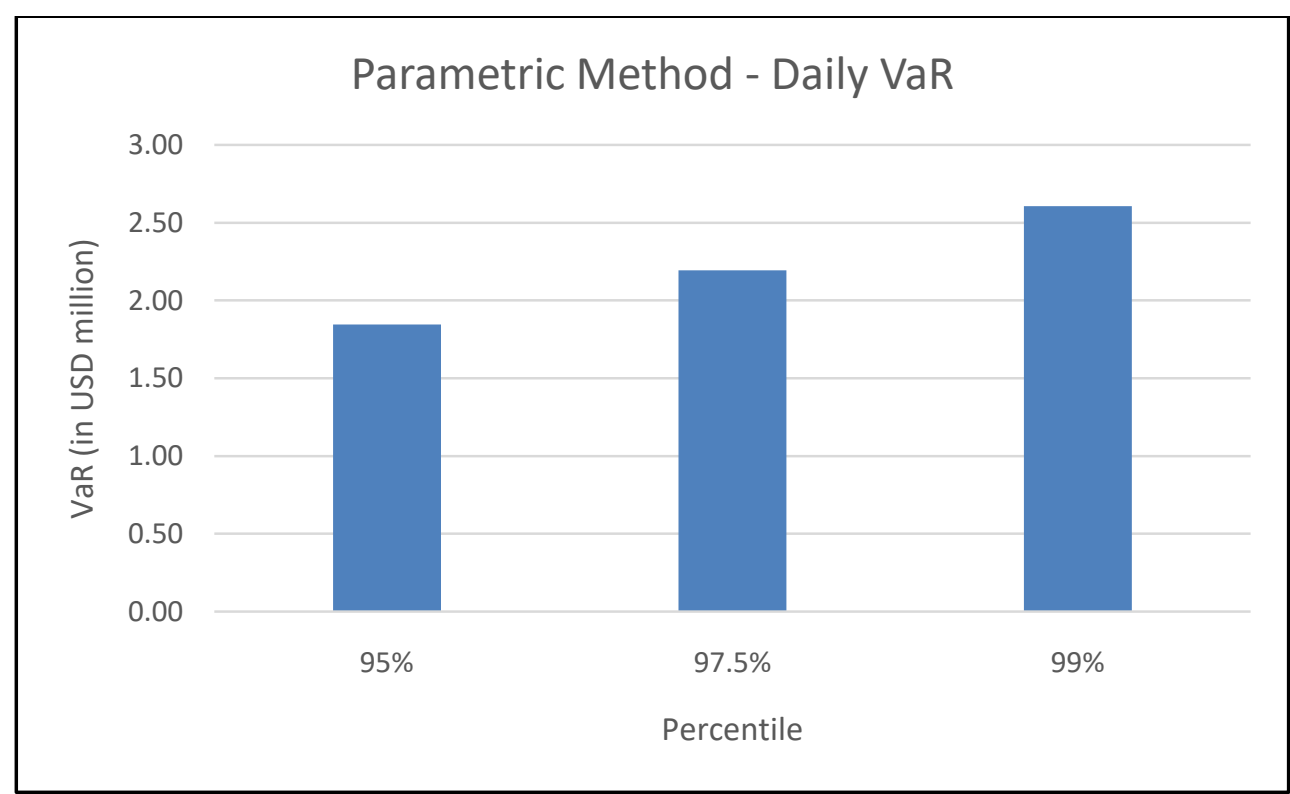

Figure 3. Daily VaR in USD (million) using Parametric method at three levels of confidence Data Source: Bloomberg 


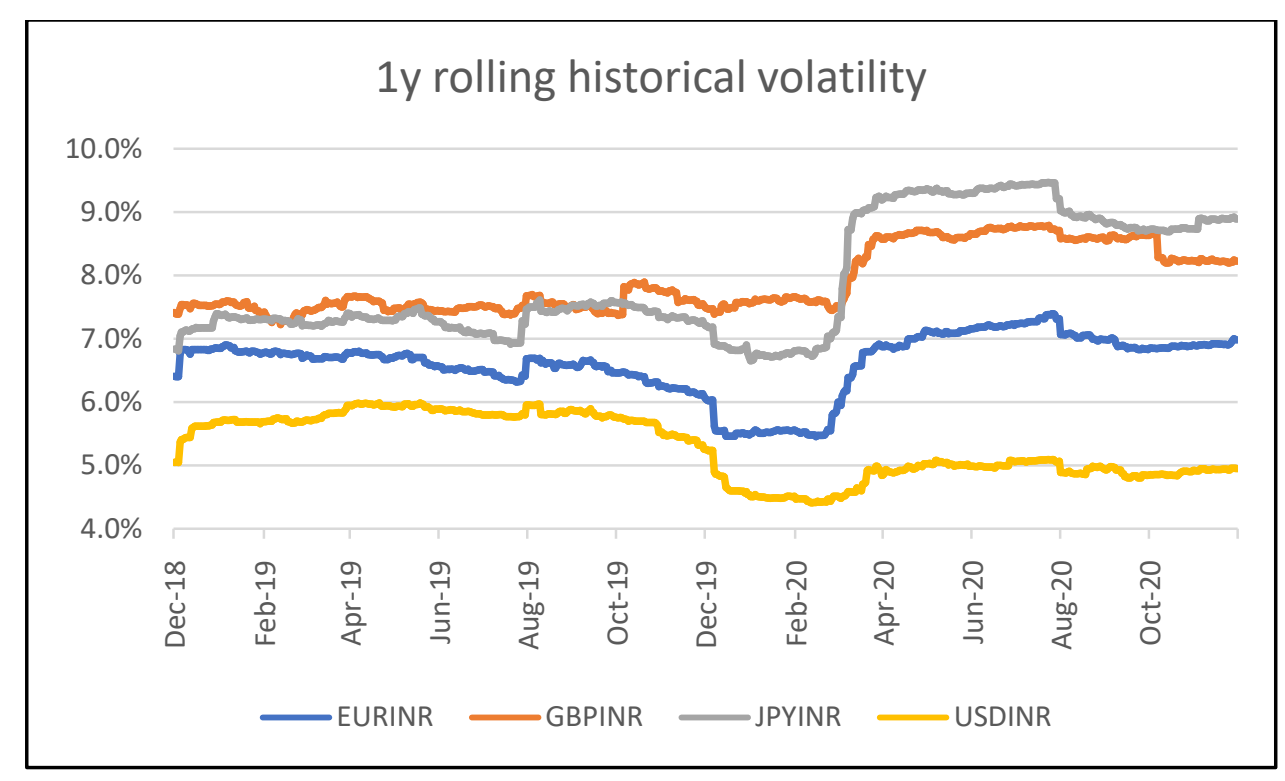

Figure 4. Historical volatility in four currency pairs for 1 year tenor Data Source: Bloomberg.

There is some difference in VaR estimation between historical and parametric methods, due to differences in assumptions. Also, given that the historic method in our sample includes the COVID-19 sell-off of 2020, it is likely to show higher VaR numbers due to the incorporation of this fat-tail event. Annual VaR can be estimated using the below relation

$$
\text { Annual VaR }=\text { Daily VaR } * \sqrt{252}
$$

Considering a daily VaR estimate of USD 2.4 million at 95\% confidence level, we arrive at an annual VaR estimate of USD 37.5 million.

The next step is to address two questions: what specific exposure does the company hedge, and how much of it? After netting off offsetting exposures, the company in our example is left with the largest exposures to EUR and JPY, which primarily drive VaR up. Given that the correlation between the two pairs is significantly and generally positive, with exposures running in opposite directions, the net amount of EUR payable remains as the key source of risk for the company. Therefore, the rest of the decision is based on what proportion of EUR exposure to hedge using FX derivatives, while hedging a small proportion of JPY exposure. It bears repeating here that the only way to achieve a zero-VaR is to $100 \%$ hedge the net exposure in each currency, which is both costly and overly conservative.

As computed above, the starting level of $\mathrm{VaR}$ when all exposures are unhedged is USD 37.5 million. While EURINR and JPYINR have a strong positive correlation, it is less than one. Hence, a small part of JPYINR exposure is likely to remain open even after netting with EURINR. In the scenario analysis that follows, we let the company hedge $10 \%$ of its JPYINR exposure and then decide how much of EURINR exposure to hedge, while keeping the other two currencies unhedged. Table 2 shows the various hedge ratios for EUR exposure, the corresponding $\mathrm{VaR}$ after the hedge is implemented, the associated cost of hedging using forwards, and the summation of $\mathrm{VaR}$ and cost of hedging. 
Table 2. comparison of $\mathrm{VaR}$ and cost at various hedge ratios for EUR exposure

\begin{tabular}{|c|c|c|c|}
\hline $\begin{array}{c}\text { Hedge Ratio } \\
\text { (net EUR exposure) }\end{array}$ & $\begin{array}{c}\text { Annual VaR } \\
\text { in \$ million } \\
\text { (95\% confidence) }\end{array}$ & $\begin{array}{c}\text { Hedge Cost (Forward) } \\
\text { in \$ million }\end{array}$ & $\begin{array}{c}\text { VaR plus Hedge Cost } \\
\text { in \$ million }\end{array}$ \\
\hline 0.1 & 34.1 & 0.9 & 35.0 \\
\hline 0.2 & 31.2 & 3.1 & 34.3 \\
\hline 0.3 & 28.8 & 5.2 & 34.0 \\
\hline 0.4 & 26.8 & 7.4 & 34.1 \\
\hline 0.5 & 25.4 & 9.5 & 34.9 \\
\hline 0.6 & 24.7 & 11.7 & 36.4 \\
\hline 0.7 & 24.8 & 13.8 & 38.6 \\
\hline 0.8 & 25.6 & 16.0 & 41.6 \\
\hline 0.9 & 27.2 & 18.1 & 45.3 \\
\hline 1.0 & 29.3 & 20.3 & 49.6 \\
\hline
\end{tabular}

Note: the scenario analysis assumes JPY exposure hedge ratio of $10 \%$ due to the imperfect correlation between EURINR and JPYINR. Forward cost is the net premium paid for EURINR and JPYINR hedge, expressed in USD million.

VaR shows a curvilinear trend: it falls as hedge ratio increases but at a slowing pace. The first order derivative is negative but the second order derivative is positive, indicating a convex function. After a point, VaR stops reducing, flattens out, and then starts increasing again. This is because a very high hedge ratio begins to nullify the diversification benefit arising from correlations among currencies. Cost of hedge, on the other hand, generally follows a linear trend. It rises almost one-to-one with higher hedge ratio, but in cases it could rise faster if large trade size begins to adversely affect market liquidity.

Table 2 gives us two optima: VaR is minimized at a EUR hedge ratio of $60 \%$, at USD 24.7 million. It has an associated hedge cost of USD 11.7 million. On the other hand, the total cost (VaR plus hedge cost) is minimized at a EUR hedge ratio of 30\%, at USD 34 million. The corresponding VaR is USD 28.8 million. The company can choose to minimize either of the two and settle on a hedge ratio accordingly.

The optimal hedge ratio, as in equation (4), is determined by a trade-off between hedge benefit and hedge cost. The equation is re-stated here for reference:

$$
\alpha^{i}=\frac{\mu-F^{i}+m^{i}}{a x^{i} \sigma^{2}}
$$

From this equation, we know that a higher hedge cost, $m^{i}$, should reduce the hedge ratio. Therefore, the ideal measure to minimize would be VaR plus hedge cost, as opposed to VaR alone.

Figure 5 converts this into an efficient frontier where it is clear that a hedge ratio of $60 \%$ achieves the lowest $\mathrm{VaR}$. Note that as the hedge ratio increases beyond $60 \%, \mathrm{VaR}$ begins to increase because the netting benefit against other currencies begins to get undone. This happens 
while there is concurrent increase in hedge cost, which represents an inefficient region for the corporate undertaking such hedges.

Bauwens, Ben Omrane and Rengifo (2006) adopt a similar methodology in determining the optimal allocations in an FX portfolio, that maximizes expected returns subject to a VaR constraint. Here in the case of a corporate hedger, the cost is minimized subject to a desired VaR.

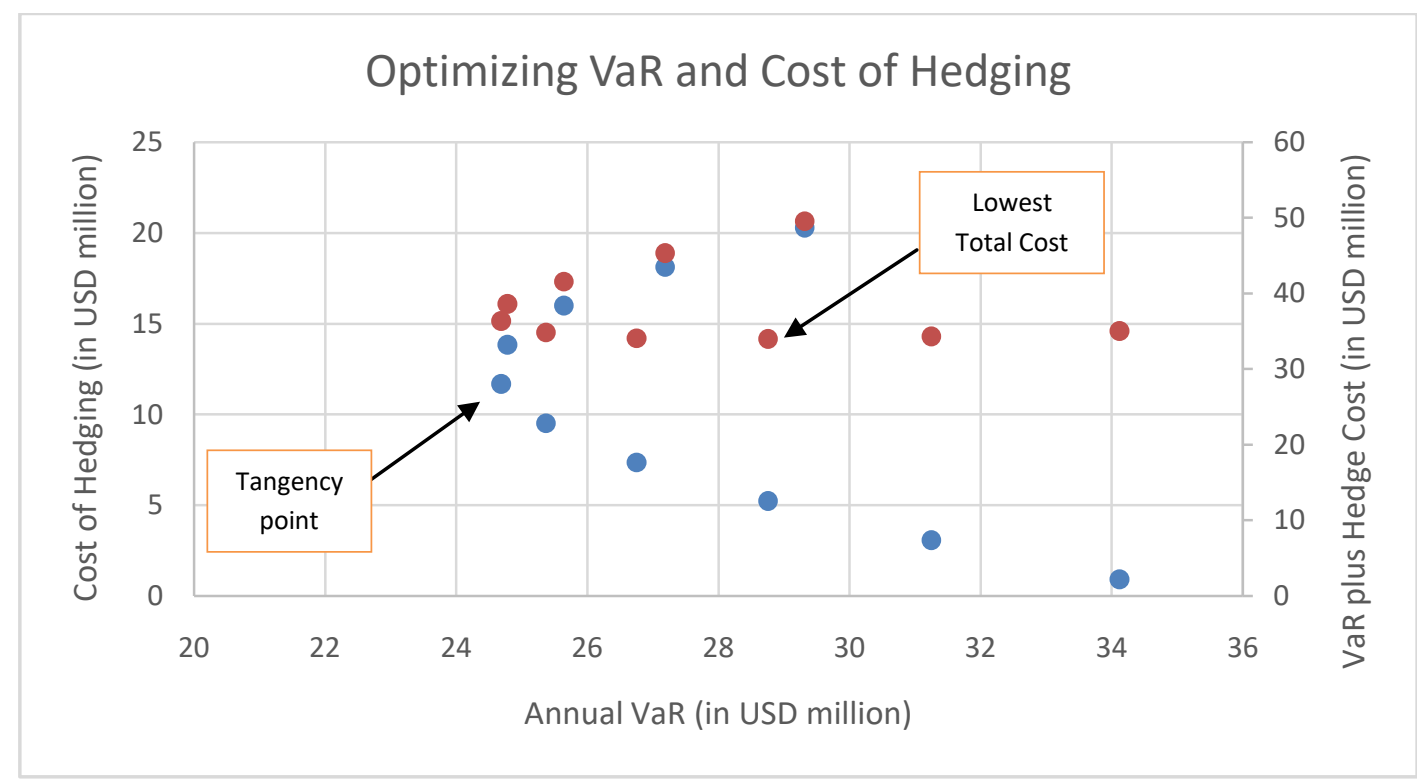

Figure 5. Comparison of $\mathrm{VaR}$ and cost of Forward hedge at various hedge ratios. Blue dots represent VaR-cost combinations and are represented along the left axis. Orange dots represent the sum of $\mathrm{VaR}$ and hedge cost and are represented along the right axis.

\section{Limitations of the Model}

\section{DISCUSSION}

Value-at-Risk has well-documented limitations as a framework. Huisman, Koedijk, and Pownall (1998) highlight how the traditional measure of VaR does not account for fat-tail events accurately enough. Given that $\mathrm{VaR}$ is a statistical measure of the risk that estimates the maximum loss that may be experienced on a portfolio with a given level of confidence, it is always connected with a probability that says how likely it is that losses will be smaller than a given number. Measuring risk in this manner can result in the corporate being exposed to fat-tail risk because VaR does not quantify the potential loss that can occur at the very end of the tail. VaR model makes an assumption that markets are behaving normally with some likelihood of major movement, while frequently financial markets do not behave normally as we have seen historically. It is important to understand that $\mathrm{VaR}$ is not designed to measure extreme price changes, and would not have been able to fully capture the market movement caused by once-ina-decade crises such as the COVID-19 pandemic. Therefore, VaR should always be interpreted along with the associated level of confidence, which is less than $100 \%$.

An organization can supplement a VaR based risk framework with stress testing. Financial parameters which demonstrate the greatest risk for the organization can be chosen and one can assess the impact of a certain percentage up or down move of that parameter. For example, in the case of the Indian exporter explored in this paper, given that the exposure in 
EUR is the largest, the firm should monitor the impact of a +- 5\% daily move in EURINR. Taken together with $\mathrm{VaR}$, this can provide a comprehensive measurement framework.

Another limitation of standalone VaR model arises when looking at multi-asset risks together. VaR takes account of how price changes of different assets are related to each other. However, the correlations between different assets are constantly changing and one has to be mindful to reassess the underlying assumptions of a hedge philosophy. For instance, JPYINR and EURINR are offsetting exposures and are positively correlated and hence can provide a good offset in our example. However, looking at historical data, the underlying correlations are volatile, moving between 0.2 and 0.8 in a year. Hence, it is important to review the correlations and resultant hedge ratios on a frequent basis.

Finally, it is critical for the organization to define hedging goals clearly. Hedging and speculating are sometimes indistinguishable (a broader definition of speculation could include amending the hedge ratio to allow for some volatility in the cash flow). Inadequate understanding of implication of hedging in terms of additional cost or opportunity loss can result in problems for treasury professionals. Using $\mathrm{VaR}$ as a tool to set these objectives is a step in reducing such subjectivity. However, it is important that goals associated with acceptable VaR levels are set and understood at senior levels in the organization. We briefly discuss hedging best practices in the next section.

\section{Best Practices for Hedging}

Hedging can often be an expensive proposition. Costs typically include hiring qualified employees in the treasury who understand the use of derivatives, credit limits with banks and associated overheads such as collateral transfer and legal documentation such as ISDA, operational costs of tracking mark-to-market on the derivative positions, and the potential gains that are foregone when uncertainty of exposure is done away with. Some of these costs can be optimized using a few simple techniques that we describe below.

Exposure optimization: as illustrated in the previous section, the recognition of offsetting exposures (within and across asset-classes) can reduce the net exposure that needs to be hedged. For instance, companies having long-term exports in USD can choose to raise USD foreign currency debt (loan/bond) to act as a natural hedge. Likewise, companies can also seek to restrict the number of invoicing currencies for exports or imports in order to keep the scope of currency exposures manageable. As a finer point, there are likely to be tenor mismatches that a corporate needs to be mindful of, such as the short-term nature of trade exposures compared to longer term nature of borrowings. Ideally, exposures should be netted off over the same time horizon when they are expected to occur, but in practice there are likely to be mismatches that need to be managed carefully.

Cross-asset correlations: in addition to the fact that currencies are correlated and hence provide natural hedge depending on the portfolio of exposures, a corporate can also consider cross-asset correlations that include exposures to commodities, fixed income instruments, and equities. Such correlations are not static and the company needs to keep monitoring these at a reasonable frequency and take an action when the correlations break down. Chen, Kritzman, and Turkington (2015) explore strategies such as linear and non-linear relations among asset classes to identify second order relationships. The use of machine learning may be particularly helpful in identifying non-linearities among financial assets. While adding layers of quantitative analyses to optimize hedging may be useful, it is computationally expensive and needs regular monitoring. 
Risk reward optimization: once the company establishes a framework of looking at overall risks by a single measure such as VaR, a risk-reward analysis can be performed comparing expected loss at a particular confidence level of $\mathrm{VaR}$ and evaluating it against the costs of running a hedge program. An optimum ratio can then be arrived at, similar to the Sharpe ratio for investment returns versus risk. This provides an objective, consistent parameter that the company can track to execute its hedge program. The simplicity of this measure does not compromise the quantitative rigor that goes into creating it.

\section{CONCLUSION}

Value-at-Risk is a widely-applied methodology for measuring risks in financial institutions. As we demonstrate in this paper, the technique can be adopted by corporate risk management as well. The basic tenets of risk measurement remain the same across organizations, whether corporate or financial, which is minimization of volatility at reasonable costs. Using VaR to measure firm-wide currency risk allows corporate to understand, measure, control and communicate the risk in a manner that can be understood at all levels in the organization.

Currency hedge decisions are always an exercise in cost-benefit analysis. Often, in times of financial market volatility, hedging activity could be hindered due to prohibitively high costs and lack of understanding of risk metrics to track. Taking a conservative approach and hedging the exposure completely could result in a very high cost for the organization. A mathematical framework that measures the risk as a single number (i.e. the impact of an adverse move to the organization) and looks at efficient ways of hedging the risk can help to resolve the dilemma to a large extent. We illustrate the case with the example of an Indian exporter firm that faces current account and capital account exposures in multiple currencies. A simple framework set at organization level can ensure that treasury professionals and senior management have clarity on the goals of hedging and the organization is protected from market volatility in a cost-efficient manner.

\section{REFERENCES}

Bauwens, L., Ben Omrane, W., \& Rengifo, E. W. (2006). Intra-daily fx optimal portfolio allocation. Available at SSRN 912697.

Chen, W., Kritzman, M., \& Turkington, D. (2015). Alternative Currency Hedging Strategies with Known Covariances. Journal of Investment Management, 13(2), 6-24.

Copeland, T., \& Copeland, M. (1999). Managing Corporate FX Risk: A Value-Maximizing Approach. Financial Management, 28(3), 68-75.

Dowd, K. (1999). A value at risk approach to risk-return analysis. The Journal of Portfolio Management, 25(4), 60-67.

Dufey, G., \& Srinivasulu, S. L. (1983). The case for corporate management of foreign exchange risk. Financial Management, 12(4), 54-62.

Hendricks, D. (1996). Evaluation of value-at-risk models using historical data. Economic policy review, 2(1), 39-69. 
Huisman, R., Koedijk, K. G., \& Pownall, R. (1998). VaR-x: Fat tails in financial risk management. Journal of risk, 1(1), 47-61.

Morgan, J. P. (1996). Riskmetrics technical document.

Marshall, C., \& Siegel, M. (1996). Value-at-Risk: Implementing a risk measurement standard.

Nain, A. (2004, March). The strategic motives for corporate risk management. In AFA 2005 Philadelphia Meetings

Rockafellar, R. T., \& Uryasev, S. (2000). Optimization of conditional value-at-risk. Journal of risk, 2(3), 21-42.

Smithson, C., \& Simkins, B. J. (2005). Does risk management add value? A survey of the evidence. Journal of applied corporate finance, 17(3), 8-17.

\section{Copyrights}

Copyright for this article is retained by the author(s), with first publication rights granted to the journal. This is an open-access article distributed under the terms and conditions of the Creative Commons Attribution license (http://creativecommons.org/licenses/by/4.0/) 